\title{
PEMBERDAYAAN MASYARAKAT MELALUI PELATIHAN PEMANFAATAN HASIL PERKEBUNAN DAN HASIL HUTAN DALAM UPAYA MENINGKATKAN PENDAPATAN MASYARAKAT DESA MEKARBUANA KECAMATAN TEGALWARU KABUPATEN KARAWANG
}

\author{
Budi Rismayadi ${ }^{1}$, Uus MD Fadli ${ }^{2}$, Mumun Maemunah ${ }^{3}$ \\ ${ }^{1}$ budi.rismayadi@ubpkarawang.ac.id \\ 2 uus.fadli@ubpkarawang.ac.id \\ 3 mumun.maemunah@ubpkarawang.ac.id \\ Universitas Buana Perjuangan Karawang
}

\begin{abstract}
ABSTRAK
Pelatihan pemanfaatan hasil perkebunan dan hasil hutan untuk meningkatkan pendapatan masyarakat yang dilaksanakan di Desa Mekarbuana memberikan dampak terhadap peningkatan pengetahuan, keterampilan dan motivasi peserta. Kegiatan dilaksanakan selama 6 bulan dengan memberikan materi antara lain pelatihan pembuatan salep/balsam dari tanaman biofarmaka, membuat minyak rambut pomade dari lilin lebah liar dan pembuatan lotion anti nyamuk dari bahan minyak sereh. Dari hasil pelatihan didirikan unit usaha Bersama yang dikelola oleh warga dan diperoleh respon yang baik dari peserta untuk meningkatkan keahlian dan pelatihan lainnya, serta pendampingan dalam menjalankan usaha.
\end{abstract}

\section{PENDAHULUAN}

Letak Kabupaten Karawang sangatlah strategis, dimana Kabupaten Karawang terhubung dengan beberapa kota-kota metropolitan, seperti Bandung, Bekasi dan Ibukota yakni Jakarta. Melihat Kabupaten Karawang yang begitu strategis, Kabupaten Karawang mulai diperhitungkan untuk membangun sebuah kawasan industri, baik yang sudah ada maupun investor yang akan menanamkan modalnya di Kabupaten Karawang. Menjadi sebuah hal yang baik bagi masyarakat dan Pemerintah Kabupaten Karawang, terciptanya lapangan pekerjaan dan memberi pendatan daerah (Amalina et al., 2018).

Pertumbuhan ekonomi dan pembangunan di daerah Karawang dalam kurun waktu sepuluh tahun terakhir menunjukkan perubahan yang cepat, dimana sektor industry dan manufaktur terus menerus bertambah dan lapangan pekerjaan yang tersedia juga setiap tahunnya mampu menyerap banyak tenaga kerja, sehingga bisa dikatakan bahwa iklim perekonomian di Karawang tumbuh dengan cukup baik.

Percepatan pembangunan di Karawang dimulai ketika sektor industrialisasi dan manufaktur membuka investasinya di Karawang sejak tahun 1990-an dan pada awal tahun 2000 an dan secara gradual proses perkembangannya menunjukkan trend yang terus meningkat setiap tahunnya (Rismayadi, 2016), demikian juga serapan lapangan kerja yang juga meningkat dan membuka kesempatan bagi masyarakat diseluruh Indonesia untuk bekerja di beberapa Kawasan industry yang ada di Karawang.

Data yang mendukung dan menjadi sebuah informasi mengenai objek kegiatan yang akan dilaksanakan, mengacu pada data dari Badan Pusat Statistik Kabupaten Karawang yang 
termuat dalam buku Kecamatan Tegalwaru dalam angka tahun 2019 untuk komoditi produksi tanaman perkebunan, sayuran dan kehutanan termasuk tanaman biofarmaka yang ada di desa Mekarbuana belum sepenuhnya dikelola dengan optimal seperti ditunjukkan dalam table 1 di bawah ini.

Tabel 1

Produksi Tanaman Biofarmaka Menurut Desa dan Jenis Tanaman di Kecamatan Tegalwaru Karawang tahun 2018 dan 2019 dalam Kg

\begin{tabular}{|c|l|c|c|c|c|c|c|c|c|}
\hline \multirow{2}{*}{ No } & \multicolumn{2}{|c|}{ Desa } & \multicolumn{2}{c|}{ Jahe } & \multicolumn{2}{c|}{ Kunyit } & \multicolumn{2}{c|}{ Laos } & \multicolumn{2}{c|}{ Temulawak } \\
\cline { 3 - 10 } & & $\mathbf{2 0 1 8}$ & $\mathbf{2 0 1 9}$ & $\mathbf{2 0 1 8}$ & $\mathbf{2 0 1 9}$ & $\mathbf{2 0 1 8}$ & $\mathbf{2 0 1 9}$ & $\mathbf{2 0 1 8}$ & $\mathbf{2 0 1 9}$ \\
\hline 1 & Cipurwasari & - & - & - & - & - & - & - & - \\
\hline 2 & Cigunungsari & 7.281 & 3.321 & - & - & - & - & - & - \\
\hline 3 & Mekarbuana & - & - & - & - & - & - & - & - \\
\hline 4 & Wargasetra & - & - & - & - & - & - & - & - \\
\hline 5 & Cintalaksana & 62.682 & 10.800 & 7.860 & 9.820 & 2.043 & 1.470 & - & - \\
\hline 6 & Cintawargi & - & - & - & - & - & - & - & - \\
\hline 7 & Cintalanggeng & - & - & - & - & - & - & - & - \\
\hline 8 & Kutamaneuh & - & - & - & - & - & - & - & - \\
\hline 9 & Kutalanggeng & - & - & - & - & - & - & - & - \\
\hline
\end{tabular}

Sumber : Buku Kecamatan Tegalwaru Dalam Angka Tahun 2019

Data statistic Kecamatan Tegalwaru menunjukkan bahwa potensi hasil panen tanaman biofarmaka diwilayah desa ini masih belum terdata, artinya untuk komoditi tanaman biofarmaka seperti jahe, lengkoas, kencur, kunyit dll belum terlaporkan sedangkan berdasarkan observasi terdapat beberapa petani yang membudidayakan tanaman ini, tentu saja perlu dilakukan penelusuran dan pengamatan lebih mendalam mengenai potensi jumlah masyarakat yang membudidayakan komoditi ini sehingga dapat dilaporkan ke BPS Karawang.

Data menunjukkan secara keseluruhan jumlah lahan yang digunakan dan menghasilkan panen produksi biofarmaka untuk jenis tanaman yang cenderung tumbuh di Kecamatan Tegalwaru ditunjukkan dalam tabel 2.

Komoditi hasil perkebunan dan hasil hutan di desa mekarbuana yang dibudidayakan oleh warga relative cukup banyak namun sebagian besar belum terdata, jenis tanaman rempahrempah yang berhasil dibudidayakan oleh masyarakat salah satunya adalah cengkeh, dan beberapa warga juga menanam tanaman sereh.

Berdasarkan hasil observasi langsung terdapat satu kelompok warga yang mengolah dan memproduksi minyak daun cengkeh dan minyak sereh melalui proses destilasi, hasil produksi minyak relative masih sedikit dan hanya untuk memenuhi pesanan yang terbatas jumlahnya, sehingga usaha ini masih belum berkembang. Dari hasil observasi tersebut penulis menganggap perlu untuk dilakukan tindak lanjut dalam bentuk kegiatan yang memberikan pelatihan dan pembinaan kepada warga serta mengedukasi agar memiliki keterampilan untuk mengolah minyak cengkeh dan minyak sereh menjadi produk lainnya sehingga dapat menghasilkan nilai tambah bagi warga. 
Tabel 2

Luas Panen Tanaman Biofarmaka Menurut Jenis Tanaman di Kecamatan Tegalwaru Karawang Tahun 2019

\begin{tabular}{|c|c|c|c|c|c|}
\hline \multirow{2}{*}{ No } & \multirow{2}{*}{ Jenis Tanaman } & \multicolumn{4}{|c|}{ Tahun } \\
\hline & & 2015 & 2016 & 2017 & 2018 \\
\hline$(1)$ & $(2)$ & (3) & (4) & $(5)$ & (6) \\
\hline 1 & Jahe & - & 240.000 & & 10.800 \\
\hline 2 & Kapulaga & - & 250.000 & 12.003 & 4.750 \\
\hline 3 & Kencur & - & 115.000 & 85.010 & 3.600 \\
\hline 4 & Kunyit & - & 272.500 & - & 2.825 \\
\hline 5 & Laos/Lengkuas & - & 215.000 & 21.001 & 2000 \\
\hline 6 & Lempuyang & - & 187.500 & 27.001 & 26.300 \\
\hline 7 & Mengkudu/Pace & - & 150.000 & 25.003 & 6000 \\
\hline 8 & Temuireng & - & 120.000 & 50.002 & 23.880 \\
\hline 9 & Temukunci & - & - & 26.001 & 8.500 \\
\hline 10 & Temulawak & - & - & - & 18.500 \\
\hline & Tegalwaru & 0 & 1.550 .000 & 246.021 & 107.155 \\
\hline
\end{tabular}

Sumber : Buku Kecamatan Tegalwaru Dalam Angka 2019

Potensi lain yang dimiliki oleh desa ini adalah pengelolaan objek wisata gunung hutan oleh perhutani yang menyebabkan masyarakat dari berbagai daerah datang berkunjung ke objek wisata ini, berdasarkan pemantauan dilapangan bahwa setiap minggu tidak kurang dari 2000 orang pengunjung datang ke desa ini untuk menikmati wisata air terjun yang ada di Kawasan hutan sekitar desa ini, atau sekedar melakukan kegiatan berpetualang di gunung Sanggabuana, (Santi Pertiwi Hari Sandi, 2019) kendala yang dihadapi kebanyakan pengunjung hanya berkunjung pada saat liburan sekolah atau hari sabtu dan minggu saja sedangkan hari hari biasa terutama pada saat musim kemarau pengunjung bekurang sehingga pendapatan masyarakat dari objek wisata menurun. Perlu dilakukan pula pelatihan membuat kerajinan tangan selain meningkatkan ekonomi masyarakat juga sekaligus melestarikan kerajinan tradisional masyarakat (Hasbullah, 2014).

Desa Mekarbuana memiliki banyak sumber air yang dapat dipergunakan untuk budidaya ikan air tawar, desa ini memiliki Balai Benih Ikan yang menyediakan benih ikan yang dapat dibudidayakan oleh masyarakat, beberapa pelatihan juga pernah diberikan kepada warga masyarakat untuk proses transformasi pengetahuan, sikap dan keterampilan dari sumber belajar kepada para santri. Pelaksanaan pelatihan kewirausahaan budi daya ikan pelatihan kewirausahaan budi daya ikan yang meliputi tujuan pemberian pengetahuan dan keterampilan (Hidayat \& Yusuf, 2011).

Selain dari potensi untuk meningkatkan kondisi perekonomian desa, tingginya pengunjung juga menyebabkan timbul permasalahan lain yaitu menumpuknya sampah yang 
bisa berakibat pada pencemaran lingkungan (Budi Rismayadi, 2017) sehingga diperlukan edukasi untuk meningkatkan kesadaran masyarakat dalam pengelolaan lingkungan sehingga permasalahan sampah dapat dikendalikan, dan menjadikan desa mekarbuana menjadi tujuan wisata yang menyenangkan dan mampu mengembangkan ekonomi desa serta meningkatkan pendapatan masyarakatnya (Budi Rismayadi \& Mumun Maemunah, 2018).

Warga desa Mekarbuana sebagian ada yang memperoleh ijin untuk mengelola lahan milik kehutanan untuk di tanami pohon dan tanaman produktif lainnya (DLH Karawang, 2007) ini cukup membantu masyarakat untuk menambah penghasilan dari komoditi perkebunan yang mereka Kelola. Namun dalam kasus lain pemanfaatan lahan pekarangan warga relative masih belum optimal, apabila setiap keluarga yang memiliki lahan pekarangan rumah nya kemudian dikelola dengan baik dan optimal maka paling tidak kebutuhan dasar dapat terpenuhi, dan jika dikembangkan lebih lanjut bukan tidak mungkin lahan pekarangan rumah dapat memberikan tambahan pendapatan bagi keluarga (Budi Rismayadi \& Tim Karawang Berkebun, 2017).

Namun demikian perlu menjadi perhatian bahwa tidak jarang semangat mengejar pendapatan dengan mengeksploitasi sumber daya hutan seringkali tidak disertai tanggung jawab untuk melakukan perlindungan, konservasi, rehabilitasi dan reklamasi hutan (Mohammad Mulyadi, 2013), sehingga tidak jarang menimbulkan persoalan baru dikemudian hari.

Sehingga perlu dilakukan pembinaan dan pendampingan secara intesnif kepada warga agar dapat mengelola sumber daya dengan baik, (Sutarto et al., 2018) edukasi terhadap masyarakat mengenai optimalisasi pemanfaatan hasil perkebunan dan hasil hutan harus terus menerus dilakukan agar produktivitasnya semakin meningkat. Dan upaya untuk memberikan kecakapan hidup bagi masyarakat (Usman, 2010).

Memperhatikan berbagai potensi dan kendala yang ada di atas maka diperlukan adanya upaya perguruan tinggi untuk turut melakukan pembinaan melalui kegiatam pengabdian. Laporan ini akan menguraikan kegiatan pengabdian kepada masyarakat dalam pemberdayaan masyarakat melalui pelatihan pemanfaatan hasil perkebunan dan hasil hutan untuk meningkatkan pendapatan masyarakat dengan titik berat pada proses pembuatan produk, pengemasan dan pemasaran hasil. Kegiatan ini diharapkan dapat meningkatkan kemampuan masyarakat dalam mengelola produktifitas hasil hutan dan perkembunan, meningkatkan nilai jual produk dan secara jangka panjang dapat meningkatkan kesejahteraan dengan meningkatkan pendapatan hasil pengolahan dan penjualan produknya.

\section{METODE PENGABDIAN}

Rumusan masalah yang digunakan adalah rumusan masalah deskriptif yang berhubungan dengan variable tertentu baik satu maupun beberapa variable, (Sugiyono, 2018) namun penulis tidak berusaha untuk membuat perbandingan antar variable maupun sampel yang diuji sehingga penelitian lebih bersifat menjelaskan variable secara mandiri. (Sholikhah, 1970) peneliti mendeskripsikan apa yang dilihat, didengar, dirasakan, dan ditanyakan umumnya baru mengenal serba sepintas terhadap informasi yang diperolehnya. 
Dijelaskan bagaimana pentingnya dokumen dalam kegiatan pelatihan (Anggito, 2018). Dokumen dimanfaatkan untuk mendukung kredibilitas hasil penelitian melalui foto atau karya tulis akademik yang ada, dalam memanfaatkan dokumen perlu dicermati kredibilitasnya agar dokumen seperti poto merupakan cerminan keadaan aslinya bukan bersifat subjektif karena ditulis sendiri oleh tokoh autobiografi tersebut

Penelitian dilakukan melalui wawancara dan pengumpulan informasi melalui form isian yang telah disediakan dan dibagikan kepada peserta pelatihan, jumlah peserta yang diteliti sebanyak 42 orang yang terdiri dari 28 orang perempuan dan 14 orang laki laki yang semuanya merupakan warga desa Mekarbuan yang berprofesi sebagai petani perkebunan milik mereka.

\section{HASIL DAN PEMBAHASAN}

Desa Mekarbuana Kecamatan Tegalwaru Karawang Jawa Barat merupakan salah satu desa yang berada sebelah selatan dan merupakan desa paling ujung karena berbatasan dengan Kawasan hutan dan gunung, Kabupaten Cianjur dan Kabupaten Bogor. Luas wilayahnya mencakup 5.937 KM persegi dengan jumlah penduduk di desa ini sebanyak 4.778 jiwa (BPS Karawang, 2019).

Potensi yang dimiliki oleh desa mekarbuana seperti kebanyakan daerah pegunungan pada umumnya lebih banyak mengandalkan hasil perkebunan dan komoditi hasil hutan yang pengelolaannyapun masih tradisional, industri perkebunan sebenarnya dapat dikembangkan mengingat prospek bisnis hasil perkebunan relative masih baik dan terlebih bisnis sector ini mampu menyediakan lapangan kerja yang sesuai dengan keahlian masyarakat yang pada akhirnya akan mampu mengatasi ketimpangan pendapatan yang terjadi (Wayan R Susila \& Idm Darma Setiawan, 2007) namun umumnya investasi pada sektor perkebunan memang membutuhkan biaya yang cukup besar disamping terkait kebijakan pemerintah daerah yang dapat dijadikan sebagai payung hukum bagi para investor (Prajogo Utomo Hadi et al., 2010).

Dari uraian di atas perlu dirancang kegiatan pemberdayaan masyarakat di desa Mekarbuana khususnya dalam memberikan pelatihan kecakapan hidup sehingga memiliki keterampilan dalam mengelola sumber daya yang ada disekitar mereka terutama komoditi hasil perkebunan dan hasil hutan, sehingga mampu menciptakan nilai tambah produksi yang pada akhirnya akan memberikan tambahan pendapatan masyarakat.

Pelatihan yang diberikan kepada warga desa mekarbuana yaitu pemanfaatan komoditas hasil perkebunan dan hasil hutan yaitu pengolahan minyak daun cengkeh dan minyak daun sereh yang diproses menghasilkan produk salep, balsam dan lotion anti nyamuk.

\section{Persepsi Responden Progam Pelatihan}

Sebelum kegiatan pelatihan dilaksanakan peserta diharuskan mengisi formulir yang berisikan beberapa pertanyaan untuk mengetahui kondisi awal dari warga mengenai pemahaman yang dimiliki warga desa Mekarbuana yang mencakup informasi potensi desa, 
pengalaman mengikuti pelatihan, minat mengembangkan usaha dan motivasi. Dari pertanyaan yang diberikan diperoleh data sebagaimana dijelaskan pada table 3 di bawah ini.

Tabel 3.

\section{Persepsi Peserta Sebelum Dilakukan Pelatihan}

\begin{tabular}{|c|c|c|c|c|c|}
\hline \multirow[t]{2}{*}{ No } & \multirow{2}{*}{\multicolumn{2}{|c|}{ Tema Kuisioner }} & \multirow[t]{2}{*}{ Pertanyaan yang diajukan } & \multicolumn{2}{|c|}{ Persepsi Peserta } \\
\hline & & & & Ada & Tidak \\
\hline \multirow{3}{*}{1.} & \multirow{3}{*}{$\begin{array}{l}\text { Informasi Potensi } \\
\text { Desa }\end{array}$} & a. & $\begin{array}{l}\text { Sosialisasi mengenai program } \\
\text { pengembangan usaha Sektor } \\
\text { perkebunan }\end{array}$ & $11,9 \%$ & $88,1 \%$ \\
\hline & & b. & Sosialisasi Tanaman Biofarmaka & $7,14 \%$ & $92,86 \%$ \\
\hline & & c. & $\begin{array}{l}\text { Sosialisasi prospek pasar } \\
\text { komoditas perkebunan }\end{array}$ & $35,7 \%$ & $64,3 \%$ \\
\hline \multirow{4}{*}{2.} & \multirow{4}{*}{$\begin{array}{l}\text { Pengalaman } \\
\text { Mengikuti Pelatihan }\end{array}$} & a. & $\begin{array}{l}\text { Kegiatan pelatihan sejenis yang } \\
\text { pernah diikuti }\end{array}$ & $14,2 \%$ & $85,8 \%$ \\
\hline & & b. & $\begin{array}{l}\text { Informasi kegiatan pelatihan } \\
\text { bagi warga }\end{array}$ & $71,5 \%$ & $28,5 \%$ \\
\hline & & c. & $\begin{array}{l}\text { Kegiatan kegiatan pelatihan } \\
\text { yang pernah diikuti oleh warga }\end{array}$ & $90,5 \%$ & $9,5 \%$ \\
\hline & & d. & $\begin{array}{l}\text { Keinginan untuk mengikuti } \\
\text { kegiatan pelatihan }\end{array}$ & $95,2 \%$ & $4,8 \%$ \\
\hline \multirow{3}{*}{3.} & \multirow{3}{*}{$\begin{array}{l}\text { Minat } \\
\text { mengembangkan } \\
\text { usaha sektor } \\
\text { perkebunan }\end{array}$} & a. & $\begin{array}{l}\text { Mendirikan unit usaha } \\
\text { komoditas perkebunan }\end{array}$ & $95,2 \%$ & $4,8 \%$ \\
\hline & & b. & $\begin{array}{ll}\text { Kebutuhan } & \text { pelatihan } \\
\text { pengembangan usaha }\end{array}$ & $97,6 \%$ & $2,4 \%$ \\
\hline & & c. & $\begin{array}{l}\text { Pendampingan terhadap unit } \\
\text { usaha }\end{array}$ & $90,5 \%$ & $9,5 \%$ \\
\hline
\end{tabular}

Sumber : hasil kuisioner di olah, 2020.

Dari table 3 diatas dapat dijelaskan mengenai informasi potensi desa Mekarbuana, bahwa sosialisasi program pengembangan usaha sektor perkebunan yang diperoleh dari warga selama ini masih sangat kecil (37 peserta pelatihan atau sebanyak 88,1\% peserta menyatakan sama sekali tidak pernah mengetahui informasi tersebut). Sosialisasi mengenai tanaman biofarmaka pun masih sangat kecil (39 orang peserta pelatihan atau sebanyak 92,86\% mengaku tidak memahami atau tidak mengenal jenis tanaman biofarmaka), demikian juga tentang sosialisasi prospek pasar komoditi perkebunan masih rendah (27 orang peserta pelatihan atau $64,3 \%$ tidak pernah menerima informasi prospek pemasaran komoditi perkebunan).

Dari pengalaman mengikuti pelatihan dapat dijelaskan bahwa warga yang pernah mengikuti pelatihan sejenis masih sedikit sebanyak 36 orang peserta pelatihan $(85,8 \%)$ mengaku tidak pernah mengikuti pelatihan sejenis yang diselenggarakan oleh pihak manapun. Sedangkan informasi kegiatan pelatihan yang disampaikan kepada warga sebanyak 30 orang $(71,5 \%)$ menyatakan mereka mengetahui informasi adanya pelatihan, dan sebanyak 38 orang $(90,5 \%)$ pernah mengikuti kegiatan pelatihan lainnya, dan peserta pelatihan sebanyak 40 orang $(95,2 \%)$ menyatakan keinginan mereka untuk mengikuti pelatihan-pelatihan. 
Dari minat untuk mengembangkan usaha sektor perkebunan, persepsi peserta mengenai mendirikan unit usaha bersama produk komoditas perkebunan sebanyak 40 orang $(95,2 \%)$ menyatakan ingin memiliki unit usaha perkebunan yang dikelola Bersama. Sebanyak 41 orang $(97,6 \%)$ menyatakan mereka membutuhkan pelatihan pengembangan usaha serta 38 orang peserta $(90,5 \%)$ menyatakan mereka membutuhkan pendampingan terhadap unit usaha yang didirikan.

\section{Proses Pelatihan}

Proses pelatihan dilakukan melalui transformasi pengetahuan dan keterampilan dari nara sumber kepada para peserta mencakup penyampaian materi pelatihan tentang pemanfaatan hasil alam, praktek pembuatan produk olahan komoditi hasil perkebunan dan hasil hutan dalam bentuk Salep, Balsam, Minyak Rambut Pomade dan Lotion Anti Nyamuk Minyak Sereh.

Proses pelatihan di laksanakan selama 6 bulan terhitung dari bulan September 2019 sampai dengan Februari 2020 yang diselenggarakan dengan tahapan antara lain :

1. Tahap sosialisasi dan pemetaan masalah dilaksanakan 2 (dua) minggu pada bulan September 2019

2. Tahap seleksi dan penerimaan peserta pelatihan dilaksanakan selama 1 (satu) minggu pada bulan September 2020

3. Tahap Kegiatan Pelatihan dibagi dalam beberapa sesi antara lain :

a. Pelatihan Pembuatan Salep, Balsem dan Minyak Rambut Pomade berbahan olahan rempah-rempah tumbuhan biofarmaka dan lilin lebah, dilaksanakan minggu kedua bulan Oktober 2019

b. Pelatihan pembuatan lotion anti nyamuk berbahan minyak sereh dilaksanakan minggu kedua dan ketiga bulan Oktober 2019.

c. Pelatihan Pengemasan dilaksanakan pada bulan Nopember 2019

d. Pelatihan pemasaran dilaksanakan pada bulan Desember 2019

4. Tahap evaluasi hasil kegiatan dilaksanakan pada bulan Januari 2020

5. Tahap penyusunan Laporan kegiatan pengabdian pada masyarakat dilaksanakan pada bulan Februari 2020.

\section{Hasil Pelatihan}

Hasil dari kegiatan pelatihan yang dilaksanakan diharapkan sesuai dengan tujuan dari kegiatan yaitu menghasilkan produk olahan hasil perkebunan dan hasil hutan serta menghasilkan unit usaha yang dikelola oleh warga desa Mekarbuana. Hasil dari kegiatan pelatihan diuraikan dalam tabel 4 di bawah ini.

Tabel 4

Pemberdayaan Masyarakat Melalui Pelatihan Pemanfaatan Hasil Perkebunan Dan Hasil Hutan Untuk Meningkatkan Pendapatan Masyarakat Desa Mekarbuana Kecamatan Tegalwaru Kabupaten Karawang

\begin{tabular}{|l|c|c|c|}
\hline No & Jenis pelatihan & Indikator Penilaian & Jawaban Responden \\
\hline
\end{tabular}




\begin{tabular}{|c|c|c|c|}
\hline \multirow[t]{5}{*}{1} & \multirow{5}{*}{$\begin{array}{l}\text { Pelatihan Pembuatan } \\
\text { Salep, Balsem dan } \\
\text { Minyak Rambut } \\
\text { Pomade berbahan } \\
\text { olahan rempah- } \\
\text { rempah tumbuhan } \\
\text { biofarmaka dan lilin } \\
\text { lebah }\end{array}$} & Ketersediaan Bahan Baku & $\begin{array}{l}\text { 92,86\% banyak dan mudah } \\
\text { di dapatkan }\end{array}$ \\
\hline & & Penguasaan Proses produksi & $\begin{array}{l}83,33 \% \text { memahami proses } \\
\text { pembuatan produk }\end{array}$ \\
\hline & & $\begin{array}{l}\text { Keseriusan peserta selama } \\
\text { Pelatihan }\end{array}$ & $\begin{array}{l}88,10 \% \text { serius mengikuti } \\
\text { pelatihan }\end{array}$ \\
\hline & & $\begin{array}{l}\text { Keinginan untuk } \\
\text { memproduksi berkelajutan }\end{array}$ & $\begin{array}{l}80,95 \% \text { serius untuk } \\
\text { melanjutkan produksi }\end{array}$ \\
\hline & & Kepuasan pelatihan & $\begin{array}{l}90,48 \% \text { sangat puas dengan } \\
\text { pelatihan yang dilaksanakan }\end{array}$ \\
\hline \multirow[t]{5}{*}{2} & \multirow{5}{*}{$\begin{array}{l}\text { Pelatihan pembuatan } \\
\text { lotion anti nyamuk } \\
\text { berbahan minyak } \\
\text { sereh }\end{array}$} & Ketersediaan Bahan Baku & $\begin{array}{l}100 \% \text { bahan baku banyak } \\
\text { dan mudah didapat }\end{array}$ \\
\hline & & Penguasaan Proses produksi & $\begin{array}{l}95,24 \% \text { memahami proses } \\
\text { pembutan produk }\end{array}$ \\
\hline & & $\begin{array}{l}\text { Keseriusan peserta selama } \\
\text { Pelatihan }\end{array}$ & $\begin{array}{l}90,48 \% \text { serius mengikuti } \\
\text { pelatihan }\end{array}$ \\
\hline & & $\begin{array}{l}\text { Keinginan untuk } \\
\text { memproduksi berkelajutan }\end{array}$ & $\begin{array}{l}76,19 \% \text { serius untuk } \\
\text { melanjutkan produksi }\end{array}$ \\
\hline & & Kepuasan pelatihan & $\begin{array}{l}92,86 \% \text { sangat puas dengan } \\
\text { pelatihan yang dilaksanakan }\end{array}$ \\
\hline \multirow[t]{5}{*}{3} & \multirow[t]{5}{*}{$\begin{array}{l}\text { Pelatihan } \\
\text { Pengemasan }\end{array}$} & $\begin{array}{l}\text { Ketersediaan Bahan } \\
\text { Kemasan }\end{array}$ & $\begin{array}{l}92,86 \% \text { banyak dan mudah } \\
\text { di dapatkan }\end{array}$ \\
\hline & & $\begin{array}{l}\text { Penguasaan Proses } \\
\text { Pengemasan }\end{array}$ & $\begin{array}{l}83,33 \% \text { memahami proses } \\
\text { pembuatan produk }\end{array}$ \\
\hline & & $\begin{array}{l}\text { Keseriusan peserta selama } \\
\text { Pelatihan }\end{array}$ & $\begin{array}{l}88,10 \% \text { serius mengikuti } \\
\text { pelatihan }\end{array}$ \\
\hline & & $\begin{array}{l}\text { Keinginan untuk } \\
\text { memproduksi berkelajutan }\end{array}$ & $\begin{array}{l}80,95 \% \text { serius untuk } \\
\text { melanjutkan produksi }\end{array}$ \\
\hline & & Kepuasan pelatihan & $\begin{array}{l}90,48 \% \text { sangat puas dengan } \\
\text { pelatihan yang dilaksanakan }\end{array}$ \\
\hline \multirow[t]{5}{*}{4} & \multirow[t]{5}{*}{ Pelatihan pemasaran } & $\begin{array}{l}\text { Pemahaman Konsep } \\
\text { pemasaran }\end{array}$ & $\begin{array}{l}71,43 \% \text { memahami konsep } \\
\text { pemasaran }\end{array}$ \\
\hline & & Minat untuk memasarkan & $\begin{array}{l}47,62 \% \text { berminat untuk } \\
\text { memasarkan sendiri } \\
52,38 \% \text { ingin memproduksi } \\
\text { saja }\end{array}$ \\
\hline & & Minat Kerjasama pemasaran & $\begin{array}{l}57,14 \% \text { ingin bekerjasama } \\
\text { dengan pengumpul }\end{array}$ \\
\hline & & $\begin{array}{l}\text { Minat mengembangkan } \\
\text { pasar }\end{array}$ & $\begin{array}{l}76,19 \% \text { belum berminat } \\
\text { untuk mengembangkan } \\
\text { pasar }\end{array}$ \\
\hline & & Kepuasan pelatihan & $\begin{array}{l}90,86 \% \text { merasa puas } \\
\text { mengikuti pelatihan }\end{array}$ \\
\hline 5 & Dampak Pelatihan & Penambahan Ilmu & $\begin{array}{l}92,86 \% \text { merasa memperoleh } \\
\text { ilmu baru }\end{array}$ \\
\hline
\end{tabular}




\begin{tabular}{|l|l|l|}
\hline \multirow{n}{*}{} & $\begin{array}{l}\text { Minat Untuk meningkatkan } \\
\text { Produksi }\end{array}$ & $\begin{array}{l}\text { 98,52\% merasa termotivasi } \\
\text { untuk meningkatkan } \\
\text { produksi }\end{array}$ \\
\cline { 2 - 3 } & $\begin{array}{l}\text { Minat untuk meningkatkan } \\
\text { kemampuan produksi }\end{array}$ & $\begin{array}{l}85,2 \% \text { berminat untuk } \\
\text { meningkatkan kemampuan } \\
\text { produksi }\end{array}$ \\
\cline { 2 - 3 } & $\begin{array}{l}\text { Harapan Kesejahteraan dari } \\
\text { hasil pelatihan }\end{array}$ & $\begin{array}{l}91,12 \% \text { berharap dapat } \\
\text { meningkatkan kesejahteraan }\end{array}$ \\
\cline { 2 - 3 } & $\begin{array}{l}\text { Kepedulian terhadap } \\
\text { kelestarian lingkungan }\end{array}$ & $\begin{array}{l}\text { 92,14\% merasa peduli } \\
\text { dengan kelestarian } \\
\text { lingkungan }\end{array}$ \\
\hline
\end{tabular}

Sumber : Data Kuesioner, 2020

Dari hasil pelatihan pemberdayaan masyarakat yang telah dilaksanakan dapat djelaskan sebagai berikut :

1. sumber bahan baku di Desa Mekarbuana cukup melimpah, walau belum ada kepastian jumlah, tetapi masyarakat meyakini bahwa bahan baku produksi akan tersedia dan berkelanjutan sehingga memungkinkan produksi bisa bertahan secara jangka Panjang.

2. masyarakat sangat respon terhadap berbagai inovasi yang dikembangkan oleh perguruan tinggi apalagi pada bahan baku dan tidak bertolak belakang dengan konsep kearifan lokal, seperti dalam pola tanam, panen, pengelolaan produksi serta kerjasama dalam kelompok masyarakat.

3. Peserta memiliki pengetahuan dan keterampilan (skill) dalam mengolah hasil perkebunan dan hasil hutan menjadi produk yang memiliki nilai tambah yaitu mengolah tanaman biofarmaka menjadi produk salep/balsam, pomade dan lotion anti nyamuk.

4. Peserta mendirikan kelompok usaha Bersama untuk mengelola hasil perkebunan dan hasil hutan serta menghasilkan produk olahan.

5. Produk yang dihasilkan masih dalam proses untuk melengkapi perijinan dari dinas Kesehatan dan BPOM sebelum diperjual belikan kepada umum.

\section{KESIMPULAN}

Pelatihan pemanfaatan hasil perkebunan dan hasil hutan yang diberikan kepada masyarakat memberikan dampak yang cukup besar terutama dalam meningkatkan pengetahuan, keahlian dan motivasi kepada masyarakat dalam meningkatkan kualitas sehingga masyarakat dapat meningkatkan taraf hidup dan kesejahteraannya.

Kegiatan pelatihan dapat dikembangkan lebih lanjut dengan cakupan jumlah peserta yang lebih banyak sehingga transformasi pengetahuan dan peningkatan keahlian masyarakat dapat lebih merata, sehingga sasaran untuk menghasilkan produk unggulan desa dapat tercapai dan mampu meningkatkan kesejahteraan masyarakat desa Mekarbuana. 


\section{DAFTAR PUSTAKA}

Amalina, Sulstio Diwilanto Binsasi, \& Hartuti Purnaweni. (2018). Kebijakan Perlindungan Lahan Pertanian Berkelanjutan di Kabupaten Karawang. Jurnal Manajemen Dan Kebijakan Publik, 3(2). https://doi.org/https://doi.org/10.14710/gp.3.2.2018.92-102

Anggito, A. dan J. S. (2018). Metodologi penelitian kualitatif - Albi Anggito, Johan Setiawan - Google Buku. In CV Jejak.

BPS Karawang. (2019). Kecamatan Tegalwaru Dalam Angka 2019. BPS Karawang. https://karawangkab.bps.go.id/publication/2019/09/26/155864cedfa7da48dc0fd5a8/keca matan-tegalwaru-dalam-angka-2019

Budi Rismayadi. (2017). Penyuluhan Kesadaran Masyarakat Seputar Kampus Universitas Buana Perjuangan Karawang Mengenai Dampak Sampah Serta Pelatihan Pemanfaatan Sampah Plastik Untuk Kegiatan Ekonomi Kreatif. Buana ilmu, 1(2). https://doi.org/https://doi.org/10.36805/bi.v1i2.418

Budi Rismayadi, \& Mumun Maemunah. (2018). Creative Economy to Increase Community Revenue Based on Tourism Object, Medalsari Village, Pangkalan District Karawang Regency. Journal of Accounting, Business and Finance Research, 3(1). https://doi.org/https://doi.org/10.20448/2002.31.28.35

Budi Rismayadi, \& Tim Karawang Berkebun. (2017). KARAWANG BERKEBUN. http://fbis.ubpkarawang.ac.id

DLH Karawang. (2007). Laporan Status Lingkungan Hidup Kabupaten Karawang Tahun 2008 Pemerintah Kabupaten Karawang Propinsi Jawa Barat. https://nebulasolution.net/pustaka/images/docs/SLHD_KAB._KERAWANG_2008.pdf

Hasbullah. (2014). Pembinaan pelaku usaha. Jurnal Kewirausahaan, Vol 13.

Hidayat, D., \& Yusuf, A. (2011). Model Pemberdayaan Kelompok Pemuda Produktif (Kpp) Melalui Pelatihan Kewirausahaan Di Pondok Pesantren Ihyahul Khoer Desa Cintalanggeng Kecamatan Tegalwaru Kabupaten Karawang. Majalah Ilmiah SOLUSI, 9(17).

Mohammad Mulyadi. (2013). PEMBERDAYAAN MASYARAKAT ADAT DALAM PEMBANGUNAN KEHUTANAN (Studi Kasus Komunitas Battang di Kota Palopo, Sulawesi Selatan) * ( ) Empowerment of Indigenous People in Development (Indigenous People Case Studies in Battang Palopo City South Sulawesi). https://doi.org/https://doi.org/10.20886/jpsek.2013.10.4.224-234

Prajogo Utomo Hadi, Pantjar Simatupang, Helena Juliani Purba, Jefferson Situmorang, Tonny S Wahyudi, Wahida, \& Sri Nuryanti. (2010). Analisis dampak investasi pertanian terhadap kinerja sektor pertanian.

http://pse.litbang.pertanian.go.id/ind/pdffiles/LHP_PUH_2010.pdf 
Rismayadi, B. (2016). Faktor-Faktor Yang Mempengaruhi Produktivitas Karyawan (Studi Kasus pada CV Mitra Bersama Lestari Tahun 2014). Jurnal Manajemen \& Bisnis Kreatif, 1(1). https://doi.org/10.36805/manajemen.v1i1.53

Santi Pertiwi Hari Sandi. (2019). Pengelolaan Modal Usaha Bagi Badan Usaha Milik Desa (Bumdes) Buana Mekar Desa Mekar Buana Kecamatan Tegal Waru. https://doi.org/https://doi.org/10.36805/jurnalbuanapengabdian.v1i1.574

Sholikhah, A. (1970). Statistik deskriptif dalam penelitian kualitatif. Komunika: Jurnal Dakwah Dan Komunikasi, 10(2). https://doi.org/10.24090/komunika.v10i2.953

Sugiyono. (2018). Metode Penelitian Kuantitatif,Kualitatif dan R\&D. In ke-26.

Sutarto, J., Mulyono, S. E., Nurhalim, K., \& Pratiwi, H. (2018). Model Pemberdayaan Masyarakat Melalui Pelatihan Kecakapan Hidup Berbasis Keunggulan Lokal Desa Wisata Mandiri Wanurejo Borobudur Magelang. In Jurnal Penelitian Pendidikan (Vol. 35). https://doi.org/10.15294/jpp.v35i1.15091

Usman, H. (2010). Model Kecakapan Hidup sebagai Alternatif Mengurangi Angka Kemiskinan. Ilmu Pendidikan, 17(1).

Wayan R Susila, \& Idm Darma Setiawan. (2007). The Role Of Estate Crop-Based Industries On Economic Growth And Equity: A Social Accounting Matrix Approach. https://doi.org/http://dx.doi.org/10.21082/jae.v25n2.2007.125-147 